\title{
PET Tracers for Imaging Cardiac Function in Cardio-oncology
}

\author{
James M. Kelly ${ }^{1,2}$ (D) John W. Babich ${ }^{1,2,3}$ \\ Accepted: 4 November 2021 / Published online: 13 January 2022 \\ (c) The Author(s) 2022
}

\begin{abstract}
Purpose of Review Successful treatment of cancer can be hampered by the attendant risk of cardiotoxicity, manifesting as cardiomyopathy, left ventricle systolic dysfunction and, in some cases, heart failure. This risk can be mitigated if the injury to the heart is detected before the onset to irreversible cardiac impairment. The gold standard for cardiac imaging in cardiooncology is echocardiography. Despite improvements in the application of this modality, it is not typically sensitive to subclinical or early-stage dysfunction. We identify in this review some emerging tracers for detecting incipient cardiotoxicity by positron emission tomography (PET).

Recent Findings Vectors labeled with positron-emitting radionuclides (e.g., carbon-11, fluorine-18, gallium-68) are now available to study cardiac function, metabolism, and tissue repair in preclinical models. Many of these probes are highly sensitive to early damage, thereby potentially addressing the limitations of current imaging approaches, and show promise in preliminary clinical evaluations.

Summary The overlapping pathophysiology between cardiotoxicity and heart failure significantly expands the number of imaging tools available to cardio-oncology. This is highlighted by the emergence of radiolabeled probes targeting fibroblast activation protein (FAP) for sensitive detection of dysregulated healing process that underpins adverse cardiac remodeling. The growth of PET scanner technology also creates an opportunity for a renaissance in metabolic imaging in cardio-oncology research.
\end{abstract}

Keywords Cardiotoxicity $\cdot$ Positron emission tomography $\cdot$ Fibroblast activation protein $\cdot$ Metabolic imaging $\cdot$ Sympathetic innervation

\section{Introduction}

With over 20 million cancer survivors predicted to be living in the USA by 2026 [1], it is increasingly important to consider the longer-term impact of cancer therapy. Many

This article is part of the Topical Collection on Nuclear Cardiology

James M. Kelly

jak2046@med.cornell.edu

John W. Babich

jwbabich@gmail.com

1 Division of Radiopharmaceutical Sciences and Molecular Imaging Innovations Institute (MI3), Weill Cornell Medicine, Belfer Research Building, Room BB-1604, 413 East 69th St, New York, NY 10021, USA

2 Citigroup Biomedical Imaging Center, Weill Cornell Medicine, New York, NY 10021, USA

3 Sandra and Edward Meyer Cancer Center, Weill Cornell Medicine, New York, NY 10021, USA survivors face a higher risk of death from cardiovascular causes than from cancer recurrence [2]. This is particularly true for survivors of childhood cancer, who exhibit a significantly higher incidence of premature cardiovascular disease than appropriately matched population samples [3-5]. Anthracycline chemotherapy is effective against a broad range of cancers, and its use to treat leukemia, lymphoma, and other solid tumors has contributed to dramatic increases in survival rates for pediatric patients [6]. More than $50 \%$ of children with cancer now receive an anthracycline as part of their treatment [3]. However, anthracyclines, such as doxorubicin, are associated with cardiotoxicity [6-8], which can manifest as cardiomyocyte hypertrophy, with progression to cardiomyopathy and eventually heart failure [3]. Subclinical left ventricular abnormalities, such as decreased mass and wall thickness or contractility, are evident in as many as $60 \%$ of survivors of pediatric cancer within 6 years of the end of treatment $[3,9]$. Doxorubicin cardiotoxicity is dose-dependent [10] and exacerbated by adjuvant therapy and chest irradiation [11, 12]. Acute cardiotoxicity is rare $(<1 \%)$ and generally reversible, while early-onset chronic 
progressive toxicity, which develops during treatment, and late-onset chronic progressive toxicity arising after therapy are often irreversible [2]. Adverse cardiac effects are classified as structural or functional, and these two may be severe and decoupled, especially in early stages of damage [13]. Children are particularly susceptible to the detrimental effects of anthracyclines: approximately $7 \%$ of survivors of childhood cancer treated with anthracyclines develop heart failure within 30 years of cancer diagnosis [3], and the risk doubles in those survivors treated with both anthracyclines and external beam radiotherapy [12].

Breast cancer survivors are also at a higher risk of developing post-treatment cardiac diseases [14, 15]. Inhibitors of the human epidermal growth factor-2 (HER-2) such as trastuzumab, are the standard of care for HER2-positive breast cancer [16]. The rate of cardiotoxicity in patients treated solely with trastuzumab is 3-7\%, and it increases when trastuzumab is used in combination with anthracyclines, paclitaxel, and/or cyclophosphamide [17]. Trastuzumab cardiotoxicity is reversible, such that decreases in left ventricular ejection fraction (LVEF) can be used to direct treatment hiatus [16]. Cardiotoxicity arising from fluoropyrimidine treatment manifests as cardiomyopathy, pericarditis, and heart failure [18] but is also reversible upon cessation of therapy [19].

Radiation therapy is also commonly used in breast cancer therapy. Due to the anatomical proximity of the breast cancer lesions and the heart, the heart is at risk of irradiation. While historically the heart was considered to be resistant to doses of radiation below $30 \mathrm{~Gy}$, several studies now indicate that radiation-induced heart disease can arise from much lower doses [20]. High radiation doses ( $>30 \mathrm{~Gy}$ ) can induce symptoms of heart disease within 1-2 years of exposure, while lower doses $(<20 \mathrm{~Gy})$ may have a latency period of more than 10 years. Radiation-induced heart disease can manifest as pericarditis, myocardial fibrosis, and, potentially, coronary artery disease [21]. Fibrosis may be asymptomatic and detected only incidentally by echocardiography scanning more than 10 years after radiation therapy [22]. Multiple strategies for reducing the cardiac impact of external beam irradiation are implemented in planning and treatment programs, but the risk of cardiac toxicity is still considerable [23]. To maximize the success of these strategies requires more complete understanding of the pathophysiology of radiation-induced damage and therefore early detection of cardiac injury. This is challenging due to the long latency period between radiotherapy and the onset of symptoms of heart disease [20].

The financial, medical, and health costs of chronic heart disease in cancer survivors are significant [24-26]. The fact that cardiotoxicity can be reversible emphasizes the importance of early detection to allow appropriate treatment strategies to be implemented. However, clinical guidelines for monitoring cardiotoxicity during and after cancer therapies are currently lacking [27]. Cardiotoxicity is broadly defined in terms of measurable changes in cardiac function and assessed by measurement of LVEF, but this measure is operator-dependent [28], and a poor index of early myocardial damage $[11,28,29]$, that does not adequately predict subsequent declines in function [11]. Moreover, a sizeable proportion of heart failure patients present with preserved LVEF [30]. Routine echocardiographic screening of survivors of childhood cancer increases life expectancy and quality-of-life years relative to no screening, but gains to date are modest [26]. Cardiac MRI using late gadolinium enhancement currently detects some cardiac injury, but the method has shown poor diagnostic and prognostic value [31]. Few cardiovascular biomarkers aside from circulating cardiac troponins and B-type natriuretic peptide can be detected non-invasively [31, 32], but the sensitivity and specificity of these biomarkers may be insufficient to enable their use as single predictive markers [33].

Nuclear imaging with radiopharmaceuticals is emerging as a method of imaging cardiac function and pathology. It is now possible to image pathological processes, such as fibrosis, inflammation, metabolism, mitochondrial function, perfusion, and sympathetic innervation, using radiolabeled probes (Fig. 1). Assessment of myocardial perfusion using single photon computed tomography (SPECT) is now routine [34], but the proliferation of cameras for positron emission tomography (PET) as well as probes labeled with shortlived radioisotopes that can be incorporated into substrates or substrate analogues of numerous biological pathways make this technology a viable tool for cardio-oncology [35, 36]. In comparison to SPECT imaging, PET imaging benefits from higher count sensitivity, robust attenuation correction, and enhanced anatomical information via hybrid PET/CT and PET/MRI devices [35]. Given these characteristics, PET imaging can be exploited for imaging individual biochemical pathways implicated in numerous cardiac pathophysiologies. In this review, we discuss emerging PET probes for imaging incipient cardiac damage arising from cancer therapy.

\section{Myocardial Perfusion}

Myocardial perfusion imaging remains the most common application of radionuclide imaging in nuclear cardiology and cardio-oncology. Perfusion imaging measures coronary microvascular function, which may be disrupted in patients with coronary artery disease [37]. Both $\left[{ }^{82} \mathrm{Rb}\right] \mathrm{Rb}^{+}$ and $\left[{ }^{13} \mathrm{~N}\right]$ ammonia are routinely used in clinical practice for quantification of myocardial perfusion and myocardial perfusion reserve. A newer agent labeled with fluorine-18, $\left[{ }^{18} \mathrm{~F}\right]$ flurpiridaz, recently completed a phase III trial in which coronary artery disease was detected with greater 


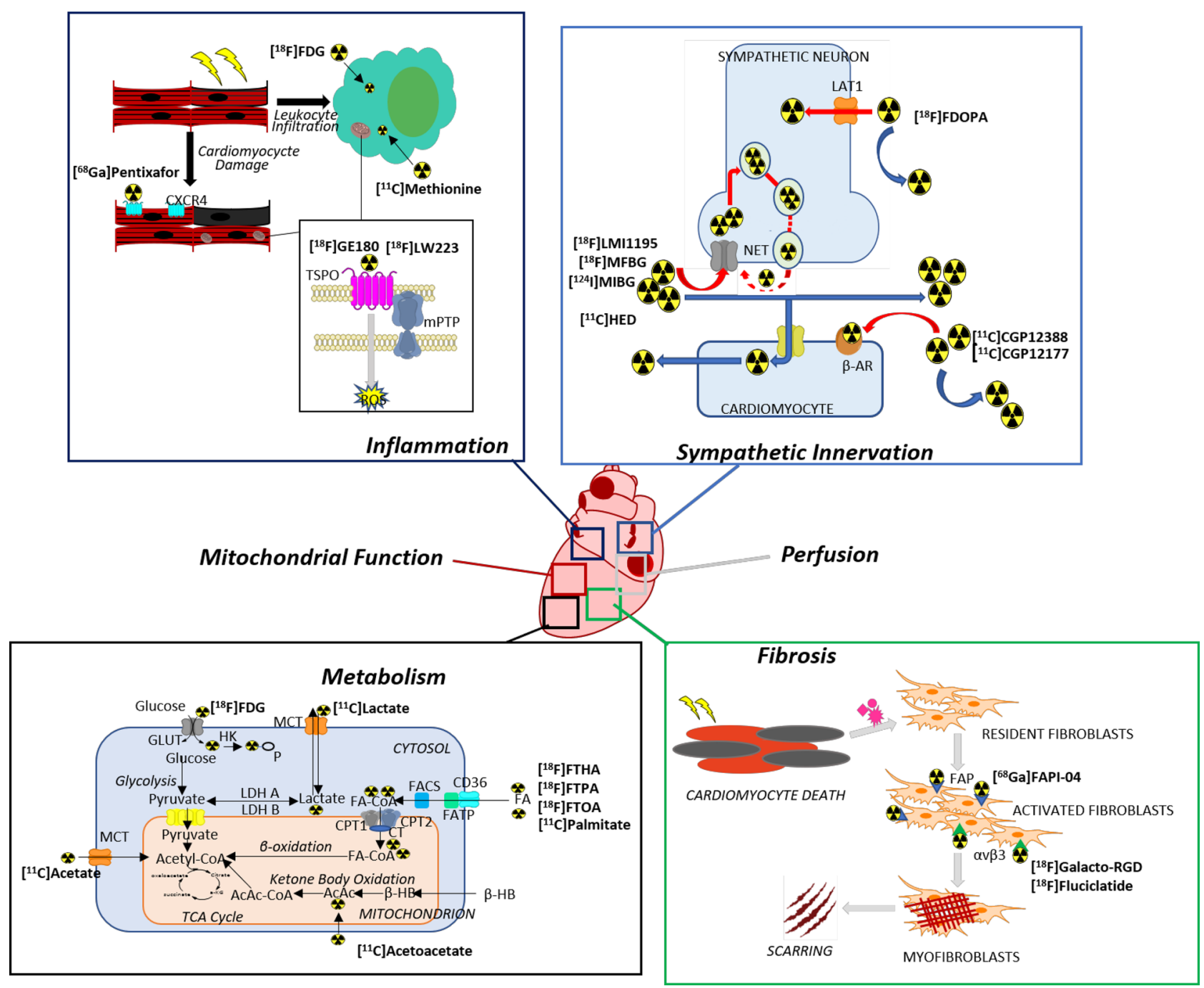

Fig. 1 Overview of cardiac functions and pathophysiological pathways in cardiotoxicity for which emerging PET tracers are proposed to have diagnostic or prognostic function. Leading examples of tracers for each of pathway are discussed in the following sections and their molecular or biochemical targets are indicated in the panels. Abbreviations: $\mathrm{CXCR} 4=\mathrm{C}-\mathrm{X}-\mathrm{C}$ chemokine receptor type $4 ; \mathrm{TSPO}=18-\mathrm{kDa}$ translocator protein; $\mathrm{mPTP}=$ mitochondrial permeability transition pore; $\mathrm{ROS}=$ reactive oxygen species;

sensitivity than ${ }^{99 \mathrm{~m}}$ Tc SPECT [38]. $\left[{ }^{18}\right.$ F]Flurpiridaz potentially exploits the superior physical properties of fluorine-18 compared to nitrogen-13 and rubidium-82. Recently, these tracers have found application in cardio-oncology to image compromised heart function as a result of cancer therapy. Myocardial perfusion reserve as assessed by $\left[{ }^{82} \mathrm{Rb}\right] \mathrm{Rb}^{+}$ PET decreased following doxorubicin exposure in a cohort of lymphoma patients [37]. A similar finding was recently reported for breast cancer patients receiving radiotherapy using $\left[{ }^{13} \mathrm{~N}\right]$ ammonia PET [39]. The prognostic value of these changes in myocardial perfusion reserve is yet to be established.
$\mathrm{LAT}=\mathrm{L}$-amino acid transporter; NET = norepinephrine transporter; $\beta$ - $\mathrm{AR}=\beta$-adrenergic receptor; $\mathrm{FAP}=$ fibroblast activation protein; GLUT $=$ glucose transporter; $\mathrm{HK}=$ hexokinase; $\mathrm{MCT}=$ monocar boxylate transporter; $\mathrm{LDH}=$ lactate dehydrogenase; $\mathrm{FA}=$ fatty acid; FATP $=$ fatty acid transport protein; FACS $=$ fatty acid-CoA synthetase; $\quad \mathrm{CPT}=$ carnitine palmitoyltransferase; $\quad \mathrm{CT}=$ carnitine acyltransferase; $\quad \mathrm{TCA}=$ tricarboxylic acid; $\mathrm{AcAc}=$ acetoacetate; $\beta$-HB $=\beta$-hydroxybutyrate

\section{Mitochondrial Dysfunction}

Doxorubicin accumulates in mitochondria over time [40]. Accumulation of doxorubicin may damage mitochondria through disruption of the electron-transport chain and the generation of free radicals [41, 42]. Given the enrichment of mitochondria in cardiomyocytes, selective damage to mitochondria may be a major mechanism of cardiotoxicity induced by doxorubicin. One method of assessing mitochondrial function is to measure the mitochondrial membrane potential. Mitochondrial membrane potential reflects aerobic energy production as well as other mitochondrial 
functions such as $\mathrm{Ca}^{2+}$ import or NADPH generation [43]. Membrane potential can be quantitated by measuring the distribution of radiolabeled probes. For example, lipophilic cationic agents used to image cardiac perfusion are also sensitive to changes in the mitochondrial membrane potential [44]. More than $90 \%$ of the cardiac accumulation of ${ }^{99 \mathrm{~m}} \mathrm{Tc}-$ MIBI is due to its trapping in mitochondria $[45,46]$. On this basis, radiolabeled cations have been proposed to be tools for non-invasive assessment of mitochondrial dysfunction arising from cardiotoxicity [46]. Loss of ${ }^{99 \mathrm{~m}} \mathrm{Tc}-\mathrm{MIBI}$ retention is evident in preclinical models of acute cardiotoxicity [44]. A recent study highlights the possibility of visualizing disrupted mitochondrial membrane potential by PET. In this study, cardiac retention of a radiolabeled phosphonium cation, $\left[{ }^{18} \mathrm{~F}\right]$ MitoPhos, decreases in a dose-dependent manner in rat hearts following doxorubicin treatment [47]. The decrease in retention in the left ventricle was nearly twofold in comparison to controls and preceded detectable changes in cardiac troponins. A similar reduction in the cardiac retention of $\left[{ }^{68} \mathrm{Ga}\right]$ Galmydar, a P-glycoprotein substrate that localizes in the mitochondria of cardiomyocytes, was also reported [48], reinforcing the promise of radiolabeled lipophilic cations for detection mitochondrial dysfunction. Future clinical evaluations are required to determine the sensitivity of this technique to anthracycline-induced cardiotoxicity.

\section{Innervation}

Serial measurement of LVEF is the gold standard for assessing cardiac function, but a sizeable proportion of heart failure patients present with preserved LVEF [30]. Activation of the cardiac nervous system is partly responsible for preservation of LVEF [49] and is therefore a pathway of interest for nuclear imaging of cardiac function. Cardiac sympathetic activation is potentially beneficial in early stages of heart failure, but its longer-term activation is detrimental [50]. Consequently, sympathetic cardiac nerve dysfunction is characteristic in cardiomyopathy, heart disease [51], and heart failure [52]. To date, multiple molecular imaging probes for imaging presynaptic neurons are in clinical use or under clinical evaluation. Norepinephrine is the major neurotransmitter of the sympathetic nervous system. Metaiodobenzylguanidine (MIBG) is a norepinephrine analogue that targets the norepinephrine transporter (NET) and shares common pathways of uptake, storage, and release with norepinephrine in presynaptic sympathetic neurons of the myocardium [50]. On this basis, radioiodinated MIBG is used for both imaging and targeted radiotherapy applications in the clinical setting. $\left[{ }^{123} \mathrm{I}\right] \mathrm{MIBG}$ scintigraphy is used for tumor imaging [53], neurodegenerative disease [54], and imaging cardiac events in heart failure [55]. Deficits in cardiac $\left[{ }^{123}\right.$ I]MIBG uptake are evident in preclinical models of anthracycline-induced cardiotoxicity $[56,57]$. Uptake also decreases in a dose-dependent manner in patients undergoing doxorubicin chemotherapy $[58,59]$. In these patients, decreases in uptake precede deterioration of LVEF, but predict subsequent decreases in heart function and progression to heart failure [59].

The clinical success of $\left[{ }^{123} \mathrm{I}\right] \mathrm{MIBG}$ has yet to be translated to a corresponding PET probe, but positron-emitting analogues such as $\left[{ }^{124} \mathrm{I}\right] \mathrm{MIBG}$ and $\left[{ }^{18} \mathrm{~F}\right] \mathrm{MFBG}$ are currently in clinical evaluation for imaging neuroblastoma [60-62]. These early studies confirm high myocardiumto-mediastinum ratios (MMR) in normal rodent and human hearts. A potential benefit of $\left[{ }^{18} \mathrm{~F}\right] \mathrm{MFBG}$ relative to $\left[{ }^{123 / 124} \mathrm{I}\right] \mathrm{MIBG}$ is the decrease in radiation dose due to the shorter half-life of fluorine-18 $\left(\mathrm{t}_{1 / 2}=110 \mathrm{~min}\right)$ and avoidance of radioactivity accumulation in the thyroid [60]. Moreover, the uptake of $\left[{ }^{18} \mathrm{~F}\right] \mathrm{MFBG}$ corresponds with NET expression [63]. These characteristics also translate favorably to application to myocardial PET imaging. $\left[{ }^{18} \mathrm{~F}\right]$ LMI1195, a radiofluorinated NET substrate, also exploits the favorable physical properties of fluorine-18. In preclinical models, $\left[{ }^{18} \mathrm{~F}\right] \mathrm{LMI} 1195$ uptake and retention in the healthy myocardium is comparable to $\left[{ }^{123} \mathrm{I}\right] \mathrm{MIBG}$ with improved contrast to normal tissue and high sensitivity to denervation $[64,65] .\left[{ }^{18} \mathrm{~F}\right] \mathrm{LMI} 1195$ has completed phase 1 [66] and phase 2 [67] clinical trials and $\left[{ }^{18} \mathrm{~F}\right] \mathrm{MFBG}$ is currently in Phase 1/2 trials for imaging myocardial sympathetic innervation [68], leading to the possibility of image cardiac denervation in the clinic by PET in the near future.

An alternative to imaging NET expression and activity in heart failure is to image the utilization of radiolabeled norepinephrine analogues by PET. Hydroxyephedrine is one such synthetic analogue that accumulates in nerve terminals and is transported into neurons by NET. Within neurons, hydroxyephedrine is transported into storage vesicles. Preclinical studies confirm that meta- $\left[{ }^{11} \mathrm{C}\right]$ hydroxyephedrine $\left(\left[{ }^{11} \mathrm{C}\right] \mathrm{HED}\right)$ is characterized by high selectivity, long neuronal retention times, likely due to dynamic recycling of $\left[{ }^{11} \mathrm{C}\right] \mathrm{HED}$ by cardiac sympathetic neurons, and high correlation with tissue norepinephrine concentrations. The recycling of this probe by cardiac sympathetic neurons likely renders its retention in neurons sensitive to changes in nerve density, NET activity, vesicular storage, and possibly sympathetic nerve activity [69]. This is demonstrated by numerous clinical imaging studies, which confirm global and regional decreases in $\left[{ }^{11} \mathrm{C}\right] \mathrm{HED}$ uptake in patients with dilated cardiomyopathy [70], acute myocardial infarction [71], and congestive heart failure [72]. Similar observations were noted in a cohort of patients with coronary artery disease but no history of myocardial infarction [73], demonstrating the broad applicability of $\left[{ }^{11} \mathrm{C}\right]$ HED PET to multiple cardiac pathologies. Regional variation in $\left[{ }^{11} \mathrm{C}\right]$ HED uptake in patients with ischemic cardiomyopathy predicted cause-specific mortality from 
sudden cardiac arrest [74], thereby validating PET imaging of cardiac sympathetic innervation as a predictive biomarker. These studies also indicate that the volume of $\left[{ }^{11} \mathrm{C}\right]$ HED deficit is independent of LVEF and infarct volume, a finding that reinforces earlier preclinical studies [75]. Notwithstanding these encouraging studies, the requirement for an on-site cyclotron to produce carbon-11 restricts $\left[{ }^{11} \mathrm{C}\right]$ HED to a research setting.

$\left[{ }^{18} \mathrm{~F}\right]$ FDOPA broadly facilitates study of the striatal dopaminergic system, but its primary clinical application is for imaging brain [76] and neuroendocrine tumors [77]. In contrast to $\left[{ }^{11} \mathrm{C}\right] \mathrm{HED},\left[{ }^{18} \mathrm{~F}\right] \mathrm{FDOPA}$ is suitable for a centralized production and distribution paradigm. The tracer is increasingly recognized to be capable of targeting pathways in multiple disorders [78], and recent feasibility studies demonstrate its utility in imaging cardiac sympathetic denervation. In one group of patients with clinically diagnosed heart failure, regional and global deficits in $\left[{ }^{18} \mathrm{~F}\right] \mathrm{FDOPA}$ uptake, defined by decreasing MMR, relative to healthy controls [79]. Additionally, $\left[{ }^{18} \mathrm{~F}\right] \mathrm{FDOPA}$ documents cardiac sympathetic dysfunction in patients with advanced idiopathic Parkinson's disease [80].

Prolonged cardiac sympathetic activation downregulates postsynaptic $\beta$-adrenergic receptors [81]. This decrease in receptor density and occupancy has been measured in patients with nonischemic cardiomyopathy using the radiolabeled beta-blockers $\left[{ }^{11} \mathrm{C}\right] \mathrm{CGP} 12388$ [82] and $\left[{ }^{11} \mathrm{C}\right]$ CGP12177 [83]. Assessment of $\beta$-adrenergic receptor density by this means highlights a correlation between density decrease and functional improvement after beta-blocker therapy [84], suggesting the possibility of using PET imaging to identify heart failure patients that would best benefit from beta-blockers.

\section{Inflammation}

Any cardiac insult may induce inflammation, which is required to commence healing [85]. When the inflammatory response is dysregulated, resulting in either excessive or insufficient activity, then inflammation itself may contribute to tissue damage and a poorer outcome. This pathological response is thought to contribute to ventricular remodeling and adverse outcomes following myocardial infarction [86], and to accelerating damage in nonischemic cardiomyopathy as well as promoting progression to heart failure [87]. Direct infiltration of immune cells may also be a cause of cardiomyopathy [85]. Inflammation is also a hallmark of cardiotoxicity arising from anthracycline therapy [88]. The inflammatory response may be evident shortly after cardiac injury [85]. As inflammation is therefore both an index of myocardial damage and a potential opportunity for therapeutic intervention, it represents an attractive target for molecular imaging in nuclear cardiology and cardio-oncology.
There are no consensus imaging biomarkers for inflammation arising from cancer therapy. One strategy is to image immune cells that infiltrate the myocardium. Inflammatory leukocytes demonstrate elevated metabolic activity characterized by increased glucose utilization [89]. $\left[{ }^{18} \mathrm{~F}\right] \mathrm{FDG}$ is taken up avidly by metabolically-activate macrophages [90]. Consequently, recruitment of these cells as part of the inflammatory response leads to increased accumulation of $\left[{ }^{18} \mathrm{~F}\right] \mathrm{FDG}$ as visualized by PET. This was confirmed by preclinical studies in a coronary ligation-induced infarction model, for which $\left[{ }^{18} \mathrm{~F}\right] \mathrm{FDG}$ uptake peaked 5 days postinfarct and corresponded to inflammatory regions populated by CD11b + monocytes [91]. Uptake post-infarct is typically highest in the border zone of the infarcted myocardium [92] despite recruitment of inflammatory mediators to the remote myocardium [91]. These findings were reinforced in postacute myocardial infarction patients, where post-infarct $\left[{ }^{18} \mathrm{~F}\right]$ FDG uptake also correlated inversely with longer term functional outcome [93].

The use of $\left[{ }^{18} \mathrm{~F}\right] \mathrm{FDG}$ for imaging cardiac inflammation is complicated by high myocardial uptake under physiological conditions. Interpretation of the signal is further compromised by the presence of damaged cardiomyocytes whose metabolism may be reprogrammed. Pre-scan myocardial suppression protocols attempt to suppress the contribution of cardiomyocytes to $\left[{ }^{18} \mathrm{~F}\right] \mathrm{FDG}$ uptake, but these protocols are not always effective and may manipulate the metabolism of ischemic cardiomyocytes in ways that have yet to be determined [94]. These challenges have sparked the search for new targets that would allow higher contrast between the inflamed and healthy myocardium. Methionine is taken up by inflammatory leukocytes but is not a major metabolic substrate for the healthy myocardium [95]. On this basis, $\left[{ }^{11} \mathrm{C}\right]$ methionine PET has been investigated in preclinical models of myocarditis and myocardial infarction. Uptake of the probe in rat hearts colocalized with histologicallyproven inflammatory regions, although the contrast to non-inflammatory lesions was lower than was achieved with $\left[{ }^{18} \mathrm{~F}\right]$ FDG [96]. Baseline $\left[{ }^{11} \mathrm{C}\right]$ methionine uptake in mouse hearts was indistinguishable from background, but uptake significantly increased the infarct area and corresponded to infiltration of macrophages into the damaged myocardium [97]. In a small cohort of patients with acute myocardial infarction, $\left[{ }^{11} \mathrm{C}\right]$ methionine uptake increased in the infarcted region while $\left[{ }^{18} \mathrm{~F}\right] \mathrm{FDG}$ uptake decreased [98]. Further studies in larger patient groups may better define the prognostic value of $\left[{ }^{11} \mathrm{C}\right]$ methionine inflammation imaging in the context of decreased cardiac function.

A growing number of molecular targets for imaging have been identified within cardiomyocytes and infiltrating immune cells that contribute to the inflammatory response. Translocator Protein $18 \mathrm{kDa}$ (TSPO) is expressed in the mitochondria of cardiomyocytes, where it is proposed to 
play a key role in regulating cardiac function [99]. Expression is sensitive to inflammation, and increases during myocarditis $[100,101]$ and cardiac hypertrophy induced by transverse aortic constriction (TAC) [102], where the increase is associated with oxidative stress, metabolic failure, and systolic dysfunction [102, 103]. TSPO may regulate the mitochondrial permeability transition pore (mPTP), which opens following mitochondrial swelling induced by infarction-reperfusion injury [104]. mPTP opening subsequently leads to necrosis and apoptosis. TSPO is also recognized as a marker of activated macrophages [105] that infiltrate the myocardium following pressure overload [84]. Preclinical rodent models confirm elevated uptake of the radiolabeled TSPO ligands $\left[{ }^{18} \mathrm{~F}\right] \mathrm{GE} 180[95,106 \bullet \bullet]$ and $\left[{ }^{18} \mathrm{~F}\right]$ LW223 [107] in the infarct region by $7 \mathrm{~d}$ post-infarction in concert with increases in TSPO expression. Early increases in TSPO ligand signal predict subsequent left ventricular remodeling [95] and progression to cardiomyopathy and heart failure [108]. Strikingly, the severity of inflammation at $7 \mathrm{~d}$ post-infarction coincides with increased $\left[{ }^{18} \mathrm{~F}\right] \mathrm{GE} 180$ uptake even at sites distal to the infarct and that do not exhibit infiltrating inflammatory cells [95, 109]. Moreover, $\left[{ }^{18} \mathrm{~F}\right] \mathrm{GE} 180$ signal in the remote myocardium is elevated at 8 weeks post-infarction, which is taken to be evidence of mitochondrial stress [106••]. TSPO expression is suppressed by doxorubicin [110], and treatment of isolated cardiomyocytes with TSPO ligands reduces doxorubicin-induced deficits in cardiac contractility [111]. These findings reinforce an independent role for TSPO in the progression of cardiomyopathy [112] and as an imaging target in cardio-oncology.

CXCR4 and its ligand CXCL12 mediate immune cell recruitment and are involved in multiple inflammatory conditions. In progressive atherosclerosis and acute myocardial infarction, recruitment of leukocytes to the injured region by the CXCR4/CXCL12 pair is thought to be a component of the healing response [113]. This is supported by evidence from genetic and chemical preclinical models that knockout or continuous blockade of CXCR4 exacerbates cardiac dysfunction and promotes cardiomyopathy [114, 115]. Notwithstanding these data, a single dose of antagonist at an early time point improves healing and recovery of function [116]. In this context, imaging CXCR4 expression is a promising strategy for early detection of inflammation and immune response to cardiac insult. It was recently shown that $\left[{ }^{68} \mathrm{Ga}\right] \mathrm{Ga}$-pentixafor, a high affinity antagonist of the CXCR4 receptor, accumulates in the left ventricle of mice in the 7 days following transverse aortic constriction [117]. Additionally, CXCR4-specific [ $\left[{ }^{68} \mathrm{Ga}\right] \mathrm{Ga}$-pentixafor uptake increased in the infarct region of the myocardium in an experimental model of acute myocardial infarction. In both cases, uptake correlated with infiltration of CD45 + leukocytes and CD68 + macrophages [118]. Tracer uptake peaked at day 3 post-infarct and subsequently declined. Similar findings were reported following administration of a ${ }^{68} \mathrm{Ga}$ labeled bifunctionalized recombinant murine CXCL12 probe [119]. In human acute myocardial infarction patients, changes in $\left[{ }^{68} \mathrm{Ga}\right] \mathrm{Ga}$-pentixafor uptake in infarct regions were variable [118], but negatively correlated to scar volume at follow-up [120]. These findings suggest that CXCR4 imaging may be valuable immediately after cardiac insult to assess the size of the injured area and predict healing.

\section{Fibrosis}

Myocardial fibrosis is a crucial component of cardiac dysfunction arising from cancer therapy [2, 121, 122]. Fibrosis results from the invasion of activated fibroblasts into the myocardium, with subsequent remodeling of the extracellular matrix (ECM) leading to formation of regions of reduced elasticity [123]. If the healing process is incompletely resolved, the heart undergoes adverse left ventricle remodeling [124]. Subsequently, the heart might experience dysfunction and be vulnerable to arrhythmias or ischemia [125]. These same processes also occur following myocardial infarction $[124,126]$. Biopsy is currently the gold standard for diagnosis of myocardial fibrosis [125]. Although multiple circulating biomarkers have been proposed as noninvasive means of diagnosing myocardial fibrosis, to date, only the carboxy-terminal propeptide of procollagen type I and amino-terminal propeptide of procollagen type III correlate to the collagen volume fraction [125]. Moreover, the tissue origin of these circulating enzymes cannot be determined, limiting their diagnostic accuracy.

The central role of cardiac fibroblasts in fibrosis and cardiomyopathy is well documented: a decrease in cardiomyocytes induces activation of cardiac fibroblasts and formation of a collagen scar [127]. Scarring may decrease heart muscle function and is often only visible by echocardiography after function is already compromised. Detection of this pathophysiological process at an early stage requires identification of a specific biomarker. Fibroblast activation protein alpha (FAP) may serve this role [128]. FAP is a transmembrane serine protease involved in ECM remodeling and cell migration that is expressed almost exclusively in activated fibroblasts [129]. Myocardial FAP expression increases during cardiac remodeling [129-132], but activated fibroblasts are not evident in mature scars [133]. Preclinical studies confirm the uptake of radiolabeled FAP inhibitors in the infarct region and border region of rodent hearts [126, 134]. In these models, peak uptake is reached 7 days post-infarction, with signal evident until 21 days [126]. Signal was confirmed histologically to correspond to FAP expression.

The majority of clinical FAP inhibitor PET scans have thus far been performed in cancer patients, but anecdotal observations of increased tracer uptake in patients with 
concomitant coronary artery disease attest to the potential for this technique in detecting cardiac dysfunction. [ $\left.{ }^{68} \mathrm{Ga}\right]$ FAPI-04 is a ${ }^{68}$ Ga-labeled small molecular FAP inhibitor that has been evaluated in 28 different human cancers [135]. Intense, focal uptake of [ $\left.{ }^{68} \mathrm{Ga}\right] \mathrm{FAPI}-04$ in the infarct area post-myocardial infarction is anecdotally noted in a number of human patients $[133,136,137]$. In these images, $\left[{ }^{68} \mathrm{Ga}\right]$ FAPI-04 accumulates to a minimal extent in the remote myocardium, with uptake comparable to control subjects with no cardiac damage [133]. [ ${ }^{68} \mathrm{Ga}$ ]FAPI-04 PET overestimates the infarct area, likely due to activation of fibroblasts in the infarct border zone, but no signal is evident in mature scars [133]. The specificity of [ ${ }^{68} \mathrm{Ga}$ ]FAPI-04 for activated fibroblasts may allow this probe to serve as a diagnostic biomarker. This is supported by a recent clinical report of a patient retrospectively being diagnosed with a myocardial infarction by echocardiography after intense cardiac uptake of [ $\left.{ }^{68} \mathrm{Ga}\right]$ FAPI-04 [136].

A clinical report of intense [ ${ }^{68} \mathrm{Ga}$ ]FAPI-04 accumulation in the left ventricular myocardium in a cancer patient with a history of coronary artery disease but no signs of chronic nor acute coronary syndromes identifies a possible role for this probe in the early detection of myocardial damage during cancer therapy [138]. A retrospective analysis of patients who received [ ${ }^{68} \mathrm{Ga}$ ]FAPI-04 as part of cancer staging identified a correlation between myocardial uptake of this probe and cardiac injury [139]. These findings were confirmed in a larger retrospective study of cancer patients imaged with $\left[{ }^{68} \mathrm{Ga}\right.$ ]FAPI-04, which demonstrated a correlation between signal intensity in the myocardium and cardiovascular risk factors, including a history platinum-based chemotherapeutics or chest irradiation [140••]. These studies highlight the potential utility of [ ${ }^{68} \mathrm{Ga}$ ]FAPI-04 to noninvasive detection of cardiotoxicity. Larger, prospective studies will help to define its specific value in monitoring cardiac health during cancer therapy.

Activated cardiac fibroblasts also express $\alpha_{\mathrm{v}} \beta_{3}$ integrin during pathophysiologies that lead to extracellular matrix remodeling [141]. This expression complements $\alpha_{v} \beta_{3}$ upregulation in vascular endothelial cells within the myocardium during states of angiogenesis post-infarction [142, 143]. Together, these observations support a central role for $\alpha_{\mathrm{v}} \beta_{3}$ integrin in angiogenesis and coordinating tissue repair after myocardial infarction [143]. On this basis, PET imaging using probes that target $\alpha_{\mathrm{v}} \beta_{3}$ integrin represents a possible method of visualizing cardiac tissue repair. In a preclinical model of coronary artery occlusion followed by reperfusion, focal uptake of the high affinity antagonist $\left[{ }^{18} \mathrm{~F}\right] \mathrm{F}-$-Galacto-arginine-glycine-aspartate (RGD) peaked between 1 and 3 weeks in the infarct area before decreasing [142]. These findings were supported by a recent study in a cohort of patients with acute myocardial infarction [143]. Focal myocardial uptake of $\left[{ }^{18} \mathrm{~F}\right]$ fluciclatide, a high affinity RGD-derived ligand, in these patients colocalized to the infarct region. Moreover, $\alpha_{\mathrm{v}} \beta_{3}$ integrin expression, as determined by $\left[{ }^{18} \mathrm{~F}\right]$ fluciclatide PET, increases in aortic atherosclerotic plaques, and this is particularly evident in patients with recent myocardial infarction [144]. These preliminary studies identify $\alpha_{\mathrm{v}} \beta_{3}$ integrin as a potential imaging biomarker of inflammation and cardiac remodeling, though studies in larger cohorts are necessary to determine the sensitivity and prognostic value of this candidate biomarker.

\section{Metabolism}

The majority of energy metabolism in the healthy heart is oxidative phosphorylation, which supplies more than $95 \%$ of ATP generated in the heart [145]. The major driving force of this ATP production, supplying approximately $70 \%$, is $\beta$-oxidation of fatty acids. The remaining supply of ATP is produced from oxidation of glucose, lactate, or ketone bodies. Experimental models indicate that fatty acid utilization substantially decreases in hypertrophy, cardiomyopathy and heart failure. This may result in a compensatory increase in glucose oxidation, but results published to date are inconsistent in this regard. A confounding factor may be the increase of anaplerosis, which diverts pyruvate away from mitochondrial oxidation and potentially decouples glycolysis and glucose oxidation. Preclinical and preliminary clinical studies using radiolabeled myocardial metabolic substrates or substrate analogues support the application of metabolic PET imaging to detection of myocardial ischemia, assessment of viability, and early detection of cardiomyopathy [146].

Radiolabeled fatty acids and fatty acid analogues have long been investigated for noninvasive measurement of myocardial metabolism in the context of ischemia and cardiomyopathy [147]. [ $\left.{ }^{11} \mathrm{C}\right]$ Palmitate is rapidly taken up homogenously by healthy human and animal hearts [148], and its washout is proposed to reflect both fatty acid $\beta$-oxidation (rapid) and incorporation into the cardiomyocyte triglyceride pool (slow) [146]. Under ischemic conditions or during ischemic dilated cardiomyopathy, $\left[{ }^{11} \mathrm{C}\right]$ palmitate uptake decreases $[149,150]$. This is attributed to diminished capacity of the myocardium to extract, retain, and metabolize long-chain fatty acids [151] and enables delineation of the infarct area based on regional defects of [ $\left.{ }^{11} \mathrm{C}\right]$ palmitate uptake [149]. By contrast, the myocardial distribution of $\left[{ }^{11} \mathrm{C}\right]$ palmitate is more heterogenous in patients with nonischemic dilated cardiomyopathy [152]. The acquisition of dynamic PET images following administration of $\left[{ }^{11} \mathrm{C}\right]$ palmitate enables myocardial fatty acid utilization and myocardial fatty acid oxidation to be qualitatively estimated after application of a suitable kinetic model. Nevertheless, the distribution of radiolabeled fatty acids into multiple lipid pools with different kinetics complicates the measurements of uptake and myocardial metabolism kinetics [147, 148]. Both a four-compartment model [153-155] 
and a three-tissue compartment model [156, 157] have been proposed for analysis of the kinetic data. To date, the majority of these kinetic analyses have been carried out in animal models, highlighting the knowledge gap that must be bridged before these probes become clinically routine.

$\left[{ }^{18}\right.$ F $]$ Fluoro-6-thia-heptadecanoic acid, $\left[{ }^{18} \mathrm{~F}\right] \mathrm{FTHA}$, utilizes a sulfur atom in the fatty acid backbone to inhibit $\beta$-oxidation [158]. In contrast to $\left[{ }^{11} \mathrm{C}\right]$ palmitate, this probe is not fully metabolized and therefore quantitation of uptake is possible after correcting the arterial input function for plasma metabolites [147]. By comparison to $\left[{ }^{11} \mathrm{C}\right]$ palmitate and 17- $\left[{ }^{18} \mathrm{~F}\right]$ fluoroheptadecanoic acid [159], myocardial uptake of $\left[{ }^{18} \mathrm{~F}\right] \mathrm{FTHA}$ is similar, but its clearance is significantly slower [158]. The rate of $\left[{ }^{18} \mathrm{~F}\right] \mathrm{FTHA}$ uptake increases in patients with congestive heart failure [160]. The second- and thirdgeneration analogues $16-\left[{ }^{18} \mathrm{~F}\right]$ fluoro-4-thia-palmitate and 18- $\left[{ }^{18} \mathrm{~F}\right]$ fluoro-4-thia-oleic acid, respectively, have increased specificity to myocardial fatty acid oxidation and improved myocardial retention [161, 162]. Recent in vitro studies confirm that these next-generation ${ }^{18} \mathrm{~F}$-fluorinated thia-oleic acid derivatives are also taken up by fatty acid transporters and are retained in cardiomyocytes after becoming metabolically blocked in the $\beta$-oxidation pathway [163].

More recent studies also identify a possible role for metabolic PET imaging in assessing cardiotoxicity arising from cancer treatment [164-167]. As energy production is essential to cardiac function, the metabolic pathways that drive this process represent promising candidates for early identification of cardiotoxicity. $\left[{ }^{18} \mathrm{~F}\right] \mathrm{FDG}$ is a radiolabeled glucose analogue that is trapped in cells following its phosphorylation by hexokinase. Consequently, it is used to assess myocardial glycolytic flux. A reduction in $\beta$-oxidation may induce a compensatory increase in glycolysis that could be visualized non-invasively by $\left[{ }^{18} \mathrm{~F}\right] \mathrm{FDG}$ PET. Increased glucose utilization, as indicated by increased $\left[{ }^{18} \mathrm{~F}\right] \mathrm{FDG}$ uptake, is evident in rat hearts following treatment with sunitinib [164]. Moreover, cardiac uptake of $\left[{ }^{18} \mathrm{~F}\right] \mathrm{FDG}$ increases in lung cancer [166] and esophageal cancer [167] patients treated with radiotherapy and in lymphoma patients treated with anthracyclines [168•]. However, while $\left[{ }^{18} \mathrm{~F}\right] \mathrm{FDG}$ signal increase correlated with LVEF decrease in these patients, the studies were largely conducted retrospectively. Prospective and long-term studies are needed to confirm an association between early increase in myocardial $\left[{ }^{18} \mathrm{~F}\right] \mathrm{FDG}$ signal and later loss of function [169].

${ }^{11} \mathrm{C}$-Labeled metabolites are potentially valuable alternatives to $\left[{ }^{18} \mathrm{~F}\right] \mathrm{FDG}$ because they are fully metabolized by the heart and can therefore allow the rates of metabolic processes to be qualitatively estimated. The short halflife of carbon-11 $\left(\mathrm{t}_{1 / 2}=20.8 \mathrm{~min}\right)$ contributes to reducing the radiation dose, thereby facilitating serial scanning of patients with suspected cardiotoxicity. Typically, the rate of utilization of these probes is decreased as a consequence of metabolic impairment in the failing heart. $\left[{ }^{11} \mathrm{C}\right]$ Acetate is a tool for measuring myocardial oxygen consumption because it is readily oxidized to $\left[{ }^{11} \mathrm{C}\right] \mathrm{CO}_{2}[170]$. Regional decreases in oxidative metabolism are evident by $\left[{ }^{11} \mathrm{C}\right]$ acetate PET in patients with hypertrophic cardiomyopathy [171, 172]. Overlapping pathologies between this condition and cardiotoxicities suggest a role for $\left[{ }^{11} \mathrm{C}\right]$ acetate in the cardiooncology setting. To this end, a decreased rate of myocardial $\left[{ }^{11} \mathrm{C}\right]$ acetate utilization is evident in a preclinical model of sunitinib cardiotoxicity [164]. Similarly, $\left[{ }^{11} \mathrm{C}\right]$ acetoacetate, a ketone body, is not utilized to the same extent in the myocardium of rats with doxorubicin-induced cardiotoxicity as in healthy controls [165]. Finally, as the heart uses lactate as a source of acetyl-CoA to supply the tricarboxylic acid cycle [158], $\left[{ }^{11} \mathrm{C}\right]$ lactate is proposed to be a potential probe for assessing myocardial metabolism by PET [173]. Feasibility studies in animal models confirm that $\left[{ }^{11} \mathrm{C}\right]$ lactate PET correlates with lactate oxidation and support the addition of this probe to the toolbox of myocardial metabolic imaging agents. Despite these promising preclinical studies, the clinical application of these ${ }^{11} \mathrm{C}$-labeled probes is currently limited by the need to perform complex metabolite analysis to derive a suitable input function for kinetic modeling [148]. Nevertheless, the availability of these ${ }^{11} \mathrm{C}$-labeled probes by reliable chemistry combined with the ever-improving capabilities of clinical PET scanners supports further evaluation of metabolic imaging in assessing cardiac health and function during cancer therapy.

\section{Conclusions and Further Perspectives}

Cardiotoxicity encompasses a broad range of pathophysiological process that may ultimately lead to heart failure. Although the precise mechanisms by which cancer treatment causes cardiac damage are still being elucidated, it is likely that one or more of restricted flow, inflammation, cardiac remodeling, sympathetic denervation, and metabolic dysfunction are involved. Appropriate modification of treatment to protect the heart could dramatically increase quality of life, reduce medical expenses, and even be life-saving. Notwithstanding the major clinical challenge that cardiotoxicity poses to cancer patients, there are no reliable methods of detecting incipient cardiac injury before the damage is irreversible. Therefore, there is both a great need and an unprecedented opportunity for molecular imaging probes to identify the pathophysiological processes that underpin cardiotoxicity even when patients present with preserved LVEF or normal echocardiographic scans. As many of these processes overlap with those that arise as a result of other chronic or acute myocardial insults, the evaluation of new PET tracers in patients with heart failure promises to be of 
great value to cardio-oncology. In this review, we highlight the preclinical and clinical evidence for markers of perfusion, mitochondrial function, inflammation, fibrosis, and cardiomyocyte metabolism as diagnostic and predictive biomarkers of cardiac damage.

Among the tracers to have recently undergone clinical evaluation, radiolabeled inhibitors of fibroblast activation protein are particularly promising early markers of cardiac injury. Multiple pathways contribute to cardiomyocyte death, but cardiomyopathy is ultimately the result of functional decline of the heart due to stiffening and scarring of the muscle. Fibrosis is a key element of cardiomyopathy. Radiolabeled FAP inhibitors are synthesized in high radiochemical yields and purities and accumulate in the activated fibroblasts responsible for initiating the pathological healing response. In preliminary clinical studies, these compounds minimally accumulate in healthy tissue and rapidly clear from blood. Myocardial uptake is not restricted to the specific site of injury, e.g., the infarct region, but rather reflects the regional activation of fibroblasts that contribute to scarring. Furthermore, high signal at early time points predicts later stage cardiac remodeling. On the basis of these preliminary studies, FAP appears to be both a diagnostic and predictive biomarker. FAP imaging, therefore, may be transformational in nuclear cardiology and cardio-oncology.

Finally, technological innovation in imaging physics and camera design may promote new probes to the forefront of PET imaging in cardiology and cardio-oncology. As the sophistication of PET cameras increases the metabolic information that can be extracted from imaging studies with ${ }^{11} \mathrm{C}$-labeled polar metabolites, such as $\left[{ }^{11} \mathrm{C}\right]$ acetate or $\left[{ }^{11} \mathrm{C}\right]$ lactate, may become increasingly detailed. In principle, metabolic PET imaging is not only a real-time snapshot of cardiac metabolism but also a tool for quantifying the rates of specific metabolic pathways relevant to cardiac health. The challenge of identifying a suitable kinetic model has, to date, rendered these ${ }^{11} \mathrm{C}$-labeled probes qualitative rather than measures of cardiac metabolism. Whole body scanners offer the possibility of determining the input function from a single scan rather than complex metabolite analysis, thereby addressing a major limitation of these probes. The requirement for carbon-11 likely restricts the use of probes such as $\left[{ }^{11} \mathrm{C}\right]$ lactate or $\left[{ }^{11} \mathrm{C}\right]$ acetoacetate to the research setting, but the biochemical information extracted from these ${ }^{11} \mathrm{C}$-labeled probes may complement information obtained from other imaging modalities such as SPECT and hyperpolarized magnetic resonance imaging [174] and suggest new probes labeled with fluorine-18 for assessing myocardial metabolism in large clinical populations. With these tools in hand, a renaissance in metabolic imaging as a way of non-invasively assessing cardiac health in cardio-oncology is a distinct possibility.
Acknowledgements This work was partially funded by the National Cancer Institute (R21 funding mechanism: R21CA246409) at the National Institutes of Health. The funding agency did not influence the content of this review.

\section{Declarations}

Conflict of Interest JMK and JWB hold equity in Ratio Therapeutics LLC. JWB holds equity in Ground Fluor Radiopharmaceuticals.

Human and Animal Rights and Informed Consent This article does not contain any studies with human or animal subjects performed by any of the authors.

Open Access This article is licensed under a Creative Commons Attribution 4.0 International License, which permits use, sharing, adaptation, distribution and reproduction in any medium or format, as long as you give appropriate credit to the original author(s) and the source, provide a link to the Creative Commons licence, and indicate if changes were made. The images or other third party material in this article are included in the article's Creative Commons licence, unless indicated otherwise in a credit line to the material. If material is not included in the article's Creative Commons licence and your intended use is not permitted by statutory regulation or exceeds the permitted use, you will need to obtain permission directly from the copyright holder. To view a copy of this licence, visit http://creativecommons.org/licenses/by/4.0/.

\section{References}

1. American Cancer Society. Cancer treatment \& survivorship facts \& figures 2016-2017. Atlanta: American Cancer Society; 2016.

2. Bloom MW, Hamo CE, Cardinale D, Ky B, Nohria A, Baer L, et al. Cancer therapy-related cardiac dysfunction and heart failure part 1: definitions, pathophysiology, risk factors, and imaging. Circ Heart Fail. 2016;9:e002661.

3. Harake D, Franco VI, Henkel JM, Miller TL, Lipshultz SE. Cardiotoxicity in childhood cancer survivors: strategies for prevention and management. Future Cardiol. 2012;8:647-70.

4. Faber J, Wingerter A, Neu MA, Henninger N, Eckerle S, Münzel $\mathrm{T}$, et al. Burden of cardiovascular risk factors and cardiovascular diseases in childhood survivors: data from the German CVSSstudy. Eur Heart J. 2018;39:1555-62.

5. Armenian SH, Armstrong GT, Aune G, Chow EJ, Ehrhardt MJ, Ky B, et al. Cardiovascular disease in survivors of childhood cancer: insights into epidemiology, pathophysiology, and prevention. J Clin Oncol. 2018;36:2135-44.

6. Lipshultz SE, Karnik R, Sambatakos P, Franco VI, Ross SW, Miller TL. Anthracycline-related cardiotoxicity in childhood cancer survivors. Curr Opin Cardiol. 2014;29:103-12.

7. Singal PK, Iliskovic N. Doxorubicin-Induced Cardiomyopathy. New Engl. J Med. 1998;339:900-5.

8. Chatterjee K, Zhang J, Honbo N, Karliner JS. Doxorubicin cardiomyopathy. Cardiology. 2010;115:155-62.

9. Lipshultz SE, Colan SD, Gelber RD, Perez-Atayde AR, Sallan SE, Sanders SP. Late cardiac effects of doxorubicin therapy for acute lymphoblastic leukemia in childhood. N Engl J Med. 1991;324:808-15.

10. Cardinale D, Colombo A, Bacchiani G, Tedeschi I, Meroni CA, Veglia $\mathrm{F}$, et al. early detection of anthracycline cardiotoxicity and improvement with heart failure therapy. Circulation. 2015;131:1981-8. 
11. Ky B, Putt M, Sawaya H, French B, Januzzi JL Jr, Sebag IA, et al. Early increases in multiple biomarkers predict subsequent cardiotoxicity in patients with breast cancer treated with doxorubicin, taxanes and trastuzumab. J Am Coll Cardiol. 2014;63:809-16.

12. van der Pal HJ, van Dalen EC, van Delden E, van Dijk IW, Kok WE, Geskus RB, et al. High risk of symptomatic cardiac events in childhood cancer survivors. J Clin Oncol. 2012;30:1429-37.

13. Sivapackiam J, Sharma M, Schindler TH, Sharma V. PET Radiopharmaceuticals for imaging chemotherapy-induced cardiotoxicity. Curr Cardiol Rep. 2020;22:62.

14. Mehta LS, Watson KE, Barac A, Beckie TM, Bittner V, CruzFlores S, et al. Cardiovascular disease and breast cancer: where these entities intersect: a scientific statement from the American Heart Association. Circulation. 2018;137:e30-66.

15. Coughlin SS, Ayyala D, Majeed B, Cortes L, Kapuku G. Cardiovascular disease among breast cancer survivors. Cardiovasc Disord Med. 2020;2. https://doi.org/10.31487/j.cdm.2020.01.01.

16. Nowsheen S, Viscuse PV, O'Sullivan CC, Sandhu NP, Haddad $\mathrm{TC}$, Blaes A, et al. Incidence, diagnosis, and treatment of cardiac toxicity from trastuzumab in patients with breast cancer. Curr Breast Cancer Rep. 2017;9:173-82.

17. Seidman A, Hudis C, Pierri MK, Shak S, Paton V, Ashby M, Murphy $\mathrm{M}$, Stewart SJ, Keefe D. Cardiac dysfunction in the trastuzumab clinical trials experience. J Clin Oncol. 2002;20:1215-21.

18. Saif MW, Quinn MG, Thomas RR, Ernst A, Grem JL. Cardiac toxicity associated with capecitabine therapy. Acta Oncol. 2003;42:342-4.

19. Iskandar MZ, Quasem W, El-Omar M. 5-Fluorouracil cardiotoxicity: reversible left ventricular systolic dysfunction with early detection. BMJ Case Rep. 2015;2015:bcr2015209347.

20. Darby SC, Cutter DJ, Boerma M, Constine LS, Fajardo LF, Kodama K, et al. Radiation-related heart disease: current knowledge and future prospects. Int J Radiat Oncol Biol Phys. 2010;76:656-65.

21. Windisch P, Zwahlen DR, Giesel FL, Scholz E, Lugenbiel P, Debus J, et al. Clinical results of fibroblast activation protein (FAP) specific PET for non-malignant indications: systematic review. EJNMMI Res. 2021;11:18.

22. Heidenreich PA, Hancock SL, Lee BK, Mariscal CS, Schnittger I. Asymptomatic cardiac disease following mediastinal irradiation. J Am Coll Cardiol. 2003;42:743-9.

23. Chung SY, Oh J, Chang JS, Shin J, Kim KH, Chun K-H, et al. Risk of cardiac disease in patients with breast cancer: impact of patient-specific factors and individual heart dose from threedimensional radiation therapy planning. Int J Radiat Oncol Biol Phys. 2021;110:473-81.

24. Nipp RD, Kirchhoff AC, Fair D, Rabin J, Hyland KA, Kuhlthau K, et al. Financial burden in survivors of childhood cancer: a report from the Childhood Cancer Survivor Study. J Clin Oncol. 2017;35:3474-81.

25. Levitt G, Anazodo A, Burch M, Bunch K. Cardiac or cardiopulmonary transplantation in childhood cancer survivors: an increasing need? Eur J Cancer. 2009;45:3027-34.

26. Wong FL, Bhatia S, Landier W, Francisco L, Leisenring W, Hudson MM, et al. Efficacy and cost-effectiveness of the Children's Oncology Group long-term follow-up screening guidelines for childhood cancer survivors at risk of treatment-related heart failure. Ann Intern Med. 2014;160:672-83.

27. Fadol AR. Management of chemotherapy-induced left ventricular dysfunction and heart failure in patients with cancer while undergoing cancer treatment. The MD Anderson Practice. Front Cardiovasc Med. 2018;5:24.

28. Thavendiranathan P, Grant AD, Negishi T, Plana JC, Popović ZB, Marwick TH. Reproducibility of echocardiographic techniques for sequential assessment of left ventricular ejection fraction and volumes: application to patients undergoing cancer chemotherapy. J Am Coll Cardiol. 2013;61:77-84.
29. Carrió I, Estorch M, Berná L, López-Pousa J, Tabernero J, Torres G. Indium-111-antimyosin and iodine-123-MIBG studies in early assessment of doxorubicin cardiotoxicity. J Nucl Med. 1995;36:2044-9.

30. Bhatia RS, Tu JV, Lee DS, Austin PC, Fang J, Haouzi A, et al. Outcome of heart failure with preserved ejection fraction in a population-based study. N Engl J Med. 2006;355:260-9.

31. Yu AF, Ky B. Roadmap for biomarkers of cancer therapy cardiotoxicity. Heart. 2016;102:425-30.

32. Skovgaard D, Hasbak P, Kjær A. BNP predicts chemotherapyrelated cardiotoxicity and death: comparison with gated equilibrium radionuclide ventriculography. PLoS One. 2014;9:e96736.

33. Vogelsang TW, Jensen RJ, Hesse B, Kjær A. BNP cannot replace gated equilibrium radionuclide ventriculography in monitoring of anthracycline-induced cardiotoxicity. Int J Cardiol. 2008;124:193-7.

34. Trägardh E, Hasbak P, Hesse B. Myocardial perfusion SPECT and SPECT/CT in interventional cardiology. Contin Cardiol Educ. 2018;4:45-50.

35. McArdle B, Dowsley TF, Cocker MS, Ohira H, deKamp RA, DaSilva J, et al. Cardiac PET: metabolic and functional imaging of the myocardium. Semin Nucl Med. 2013;43:434-48.

36. Peterson LR, Gropler RJ. Radionuclide imaging of myocardial metabolism. Circ Cardiovasc Imaging. 2010;3:211-22.

37. Laursen AH, Elming MB, Ripa RS, Hasbak P, Kjær A, Køber $\mathrm{L}$, et al. Rubidium- 82 positron emission tomography for detection of acute doxorubicin-induced cardiac effects in lymphoma patients. J Nucl Cardiol. 2020;27:1698-707.

38. Maddahi J, Lazewatsky J, Udelson JE, Berman DS, Beanlands RSB, Heller GV, et al. Phase-III clinical trial of fluorine-18 flurpiridaz positron emission tomography for evaluation of coronary artery disease. J Am Coll Cardiol. 2020;76:391-401.

39. Nehmeh SA, Fox JJ, Schwartz J, Ballangrund ÅM, Schöder H, Zhao Y, et al. A pilot study of ${ }^{13} \mathrm{~N}$-ammonia cardiac PET imaging to assess subacute cardiotoxicity following adjuvant intensitymodulated radiotherapy for locally advanced breast cancer. Clin Imaging. 2020;68:283-90.

40. Chandran K, Aggarwal D, Migrino RQ, Joseph J, McAllister D, Konorev EA, et al. Doxorubicin inactivates myocardial cytochrome $c$ oxidase in rats: Cardioprotection by Mito-Q. Biophys J. 2009;96:1388-98.

41. Davies KJ, Doroshow JH. Redox cycling of anthracyclines by cardiac mitochondria. I. Anthracycline radical formation by NADH dehydrogenase. J Biol Chem. 1986;261:3060-3067.

42. Doroshow JH, Davies KJ. Redox cycling of anthracyclines by cardiac mitochondria. II. Formation of superoxide anion, hydrogen peroxide, and hydroxyl radical. J Biol Chem. 1986;261:3068-3074.

43. Gerencser AA, Chinopoulos C, Birket MJ, Jastroch M, Vitelli C, Nicholls DG, Brand MD. Quantitative measurement of mitochondrial membrane potential in cultured cells: calcium-induced de- and hyperpolarization of neuronal mitochondria. J Physiol. 2012;12:2845-71.

44. Safee ZM, Baark F, Waters ECT, Veronese M, Pell VR, Clark JE, et al. Detection of anthracycline-induced cardiotoxicity using perfusion-corrected ${ }^{99 \mathrm{~m}} \mathrm{Tc}$ sestamibi SPECT. Sci Rep. 2019;9:216.

45. Piwnica-Worms D, Kronauge J, Chiu M. Uptake and retention of hexakis (2-methoxyisobutyl isonitrile) technetium(I) in cultured chick myocardial cells. Mitochondrial and plasma membrane potential dependence. Circulation. 1990;82:1826-1830.

46. Chiu M, Kronauge JF, Piwnica-Worms D. Effect of mitochondrial and plasma membrane potentials on accumulation of hexakis (2-ethoxyisobutylnitrile)technetium(I) in cultured mouse fibroblasts. J Nucl Med. 1990;31:1646-53. 
47. McCluskey SP, Haslop A, Coello C, Gunn RN, Tate EW, Southworth R, et al. Imaging of chemotherapy-induced acute cardiotoxicity with ${ }^{18} \mathrm{~F}$-labeled lipophilic cations. J Nucl Med. 2019;60:1750-6.

48. Sivapackiam J, Kabra S, Speidel S, Sharma M, Laforest R, Salter A, et al. ${ }^{68} \mathrm{Ga}$-Galmydar: A PET imaging tracer for noninvasive detection of doxorubicin-induced cardiotoxicity. PLoS One. 2019; 14:e0215579.

49. Carrió I, Cowie MR, Yamazaki J, Udelson J, Camici PG. Cardiac sympathetic imaging with $\mathrm{mIBG}$ in heart failure. JACC Cardiovasc Imaging. 2010;3:92-100.

50. Laursen AH, Thune JJ, Hutchings M, Hasbak P, Kjaer A, Elming MB, et al. ${ }^{123}$ I-MIBG imaging for detection of anthracycline-induced cardiomyopathy. Clin Physiol Funct Imaging. 2018;38:176-85.

51. Schroeder C, Jordan J. Norepinephrine transporter function and human cardiovascular disease. Am J Physiol Heart Circ Physiol. 2012;303:H1273-82.

52. Dimitriu-Leen AC, Scholte AJHA, Jacobson AF. ${ }^{123}$ I-MIBG SPECT for evaluation of patients with heart failure. J Nucl Med. 2015;56:25S-30S.

53. Sharp SE, Trout AT, Weiss BD, Gelfand MJ. MIBG in neuroblastoma diagnostic imaging and therapy. Radiographics. 2016;36:258-78.

54. Skowronek C, Zange L, Lipp A. Cardiac 123I-MIBG scintigraphy in neurodegenerative Parkinson syndromes: performance and pitfalls in clinical practice. Front Neurol. 2019;10:152.

55. Jacobson AF, Senior R, Cerqueira MD, Wong ND, Thomas GS, Lopez VA, et al. Myocardial iodine-123 meta-iodobenzylguanidine imaging and cardiac events in heart failure. Results of the prospective ADMIRE-HF (AdreView Myocardial Imaging for Risk Evaluation in Heart Failure) study. J Am Coll Cardiol. 2010;55:2212-2221.

56. Collin B, Oudot A, Vrigneaud JM, et al. Abnormal cardiac adrenergic neuron activity assessed by ${ }^{123}$ I-MIBG is an early marker of cardiac dysfunction in doxorubicin-induced cardiomyopathy in rats. Eur J Nucl Med Mol Imaging. 2016;43(Suppl. 1):S88.

57. Wakasugi S, Fischman AJ, Babich JW, Aretz HT, Callahan RJ, Nakaki M, et al. Metaiodobenzylguanidine: Evaluation of Its Potential as a Tracer for Monitoring Doxorubicin Cardiomyopathy. J Nucl Med. 1993;34:1282-6.

58. Lekakis J, Prassopoulos V, Athanassiadis P, Kostarnis P, Moulopoulos S. Doxorubicin-induced cardiac neurotoxicity: Study with iodine 123-labeled metaiodobenzylguanidine scintigraphy. J Nucl Cardiol. 1996;3:37-41.

59. Valdés Olmos RA, ten Bokkel Huinink WW, ten Hoeve RFA, van Tinteren H, Bruning PF, van Vlies B, et al. Assessment of anthracycline-related myocardial adrenergic derangement by $\left[{ }^{123} \mathrm{I}\right]$ metaiodobenzylguanidine scintigraphy. Eur J Cancer. 1995;31A:26-31.

60. Pandit-Taskar N, Zanzonico P, Staton KD, Carrasquillo JA, Reidy-Lagunes D, Lyashchenko S, et al. Biodistribution and Dosimetry of ${ }^{18}$ F-Meta-Fluorobenzylguanidine: A First-inHuman PET/CT Imaging Study of Patients with Neuroendocrine Malignancies. J Nucl Med. 2018;59:147-53.

61. Cistaro A, Quartuccio N, Caobelli F, Piccardo A, Paratore R, Coppolino P, et al. ${ }^{124} \mathrm{I}-\mathrm{MIBG}$ : a new promising positron-emitting radiopharmaceutical for the evaluation of neuroblastoma. Nucl Med Rev Cent East Eur. 2015;18:102-6.

62. Pauwels E, Celen S, Vandamme M, Leysen W, Baete K, Bechter $\mathrm{O}$, et al. Improved resolution and sensitivity of $\left[{ }^{18} \mathrm{~F}\right] \mathrm{MFBG}$ PET compared with $\left[{ }^{123}\right.$ I]MIBG SPECT in a patient with a norepinephrine transporter-expressing tumour. Eur J Nucl Med Mol Imaging. 2021;48:313-5.

63. Turnock S, Turton DR, Martins CD, Chesler L, Wilson TC, Gouverneur V, et al. ${ }^{18} \mathrm{~F}$-meta-fluorobenzyguanidine $\left({ }^{18} \mathrm{~F}-\mathrm{mFBG}\right)$ to monitor changes in norepinephrine transporter expression in response to therapeutic intervention in neuroblastoma models. Sci Rep. 2020;10:20918.

64. Yu M, Bozek J, Lamoy M, Guaraldi M, Silva P, Kagan M, et al. Evaluation of LMI1195, a novel ${ }^{18} \mathrm{~F}$-labeled cardiac neuronal PET imaging agent, in cells and animal models. Circ Cardiovasc Imaging. 2011;4:435-43.

65. Werner RA, Rischpler C, Onthank D, Lapa C, Robinson S, Samnick $\mathrm{S}$, et al. Retention kinetics of the ${ }^{18} \mathrm{~F}$-labeled sympathetic nerve PET tracer LMI1195: comparison with ${ }^{11} \mathrm{C}$-hydroxyephedrine and ${ }^{123}$ I-MIBG. J Nucl Med. 2015;56:1429-33.

66. Sinusas AJ, Lazewatsky J, Brunetti J, Heller G, Srivastava A, Liu Y-H, et al. Biodistribution and radiation dosimetry of LMI1195: first-in-human study of a novel ${ }^{18} \mathrm{~F}$-labeled tracer for imaging myocardial innervation. J Nucl Med. 2014;55:1445-51.

67. Zelt J, Renaud J, Mielniczuk L, Gerrard L, Walter O, Guo A, et al. Fluorine-18 LMI1195 positron emission tomography provides accurate measure of cardiac sympathetic innervation compared to carbon-11 hydroxyephedrine. J Am Coll Cardiol. 2018;71(11_Supplement):A1482.

68. Open-label study of ${ }^{18} \mathrm{~F}-\mathrm{mFBG}$ for imaging myocardial sympathetic innervation. Sponsor: Illumina Radiopharmaceuticals, LLC. ClinicalTrials.gov Identifier: NCT04535193. Date accessed: 22 August, 2021.

69. Boschi S, Lodi F, Boschi L, Nanni C, Chondrogiannis S, Colletti $\mathrm{PM}$, et al. ${ }^{11} \mathrm{C}-$ Meta-hydroxyephedrine: a promising PET radiopharmaceutical for imaging the sympathetic nervous system. Clin Nucl Med. 2015;40:e96-103.

70. Hartmann F, Ziegler S, Nekolla S, Hadamitzky M, Seyfarth M, Richardt G, Schwaiger M. Regional patterns of myocardial sympathetic denervation in dilated cardiomyopathy: an analysis using carbon-11 hydroxyephedrine and positron emission tomography. Heart. 1999;81:262-70.

71. Allman KC, Wieland DM, Muzik O, DeGrado TR, Wolfe ER Jr, Schwaiger M. Carbon-11 hydroxyephedrine with positron emission tomography for serial assessment of cardiac adrenergic neuronal function after acute myocardial infarction in humans. J Am Coll Cardiol. 1993;22:368-75.

72. Vesalainen RK, Pietilä M, Tahvanainen KU, Jartti T, Teräs M, Någren $\mathrm{K}$, et al. Cardiac positron emission tomography imaging with $\left[{ }^{11} \mathrm{C}\right]$ hydroxyephedrine, a specific tracer for sympathetic nerve endings, and its functional correlates in congestive heart failure. Am J Cardiol. 1999;84:568-74.

73. Bulow HP, Stahl F, Lauer B, Nekolla SG, Schuler G, Schwaiger M, Bengel FM. Alterations of myocardial presynaptic sympathetic innervation in patients with multi-vessel coronary artery disease but without history of myocardial infarction. Nucl Med Commun. 2003;24:233-9.

74. Fallavollita JA, Heavey BM, Luisi AJ Jr, Michalek SM, Baldwa S, Mashtare TL Jr, et al. Regional myocardial sympathetic denervation predicts the risk of sudden cardiac arrest in ischemic cardiomyopathy. J Am Coll Cardiol. 2014;63:141-9.

75. Fallavollita JA, Banas MD, Suzuki G, deKamp RA, Sajjad M, Canty JM Jr. ${ }^{11} \mathrm{C}$-meta-hydroxyephedrine defects persist despite functional improvement in hibernating myocardium. J Nucl Cardiol. 2010;17:85-96.

76. Chen W, Silverman DHS, Delaloye S, Czernin J, Kamdar N, Pope $\mathrm{W}$, et al. ${ }^{18}$ F-FDOPA PET imaging of brain tumors: comparison study with ${ }^{18} \mathrm{~F}$-FDG PET and evaluation of diagnostic accuracy. J Nucl Med. 2006;47:904-11.

77. Bozkurt MF, Virgolini I, Balogova S, Beheshti M, Rubello D, Decristoforo $\mathrm{C}$, et al. Guideline for PET/CT imaging of neuroendocrine neoplasms with ${ }^{68} \mathrm{Ga}$-DOTA-conjugated somatostatin receptor targeting peptides and ${ }^{18} \mathrm{~F}$-DOPA. Eur J Nucl Med Mol Imaging. 2017;1588-1601.

78. Minn H, Kauhanen S, Seppänen M, Nuutila P. ${ }^{18}$ F-FDOPA: a multiple-target molecule. J Nucl Med. 2009;50:1915-8. 
79. Thayumanavan T, Patel C, Bal C, Seth S, Roy A, Pandey A, et al. Fluorine-18 Fluoro-L-Dihydroxyphenylalanine (F-18 FDOPA) PET-CT in evaluation of cardiac sympathetic innervation in Heart Failure patients. J Nucl Med. 2020;61(Suppl1):648.

80. Goyal H, Sharma A, Patel C, Deepak KK, Tripathi M, Gupta P, et al. Assessment of myocardial sympathetic innervation with 18F-FDOPA-PET/CT in patients with autonomic dysfunction: feasibility study in IPD patients. J Nucl Cardiol. 2021. https:// doi.org/10.1007/s12350-020-02474-w.

81. Lymperopoulos A, Rengo G, Koch WJ. The adrenergic nervous system in heart failure: pathophysiology and therapy. Circ Res. 2013;113:739-53.

82. de Jong RM, Willemsen ATM, Slart RHJA, Blanksma PK, van Waarde A, Cornel JH, et al. Myocardial beta-adrenoreceptor downregulation in idiopathic dilated cardiomyopathy measured in vivo with PET using the new radioligand $(\mathrm{S})-\left[{ }^{11} \mathrm{C}\right]$ CGP12388. Eur J Nucl Med Mol Imaging. 2005;32:443-7.

83. Tsukamoto T, Morita K, Naya M, Inubushi M, Katoh C, Nishijima $\mathrm{K}$, et al. Decreased myocardial $\beta$-adrenergic receptor density in relation to increased sympathetic tone in patients with nonischemic cardiomyopathy. J Nucl Med. 2007;48:1777-82.

84. Naya M, Tsukamoto T, Morita K, Katoh C, Nishijima K, Komatsu $\mathrm{H}$, et al. Myocardial $\beta$-adrenergic receptor density assessed by ${ }^{11} \mathrm{C}$-CGP12177 PET predicts improvement of cardiac function after carvedilol treatment in patients with idiopathic dilated cardiomyopathy. J Nucl Med. 2009;50:220-5.

85. Bengel FM, Ross TL. Emerging imaging targets for infiltrative cardiomyopathy: inflammation and fibrosis. J Nucl Cardiol. 2019;26:208-16.

86. Westman PC, Lipinski MJ, Luger D, Waksman R, Bonow RO, Wu E, Epstein SE. Inflammation as a driver of adverse left ventricular remodeling after acute myocardial infarction. J Am Coll Cardiol. 2016;67:2050-60.

87. Mann DJ. Innate immunity and the failing heart: the cytokine hypothesis revisited. Circ Res. 2015;116:1254-68.

88. Fabiani I, Aimo A, Grigoratos C, Castiglione V, Gentile F, Saccaro LF, et al. Oxidative stress and inflammation: determinants of anthracycline cardiotoxicity and possible therapeutic targets. Heart Fail Rev. 2021;26:881-90.

89. Thackeray JT, Bengel FM. Molecular imaging of myocardial inflammation with positron emission tomography postischemia. JACC Cardiovasc Imaging. 2018;11:1340-55.

90. Deichen JT, Prante O, Gack M, Schmiedehausen K, Kuwert T. Uptake of $\left[{ }^{18} \mathrm{~F}\right]$ fluorodeoxyglucose in human monocyte-macrophages in vitro. Eur J Nucl Med Mol Imaging. 2003;30:267-73.

91. Lee WW, Marinelli B, van der Laan AM, Sena BF, Gorbatov $\mathrm{R}$, Leuschner F, et al. PET/MRI of inflammation in myocardial infarction. J Am Coll Cardiol. 2012;59:153-63.

92. Vasudevan P, Gaebel R, Doering P, Mueller P, Lemcke H, Stenzel $\mathrm{J}$, et al. 18F-FDG PET-based imaging of myocardial inflammation predicts a functional outcome following transplantation of mESC-derived cardiac induced cells in a mouse model of myocardial infarction. Cells. 2019;8:1613.

93. Rischpler C, Dirschinger RJ, Nekolla SG, Kossmann H, Nicolosi $\mathrm{S}$, Hanus $\mathrm{F}$, et al. Prospective evaluation of ${ }^{18} \mathrm{~F}$-FDG uptake in post-ischemic myocardium by simultaneous PET/MRI as a prognostic marker of functional outcome. Circ Cardiovasc Imaging. 2016;9:e04316.

94. Ćorović A, Nus M, Mallat Z, Rudd JHF, Tarkin JM. PET Imaging of Post-infarct Myocardial Inflammation. Curr Cardiol Rep. 2021;23:99.

95. Thackeray JT, Hupe HC, Wang Y, Bankstahl JP, Berding G, Ross $\mathrm{TL}$, et al. Myocardial inflammation predicts remodeling and neuroinflammation after myocardial infarction. J Am Coll Cardiol. 2018;71:263-75.
96. Maya Y, Werner RA, Schütz C, Wakabayashi H, Samnick S, Lapa $\mathrm{C}$, et al. ${ }^{11} \mathrm{C}$-Methionine PET of myocardial inflammation in a rat model of experimental autoimmune myocarditis. J Nucl Med. 2016;57:1985-90.

97. Thackeray JT, Bankstahl JP, Wang Y, Wollert KC, Bengel FM. Targeting amino acid metabolism for molecular imaging of inflammation early after myocardial infarction. Theranostics. 2016;6:1768-79.

98. Morooka M, Kubota K, Kadowaki H, Ito K, Okazaki O, Kashida M, et al. ${ }^{11} \mathrm{C}$-Methionine PET of Acute Myocardial Infarction. J Nucl Med. 2009;50:1283-7.

99. Morin D, Musman J, Pons S, Berdeaux A, Ghaleh B. Mitochondrial translocator (TSPO): from physiology to cardioprotection. Biochem Pharmacol. 2016;105:1-13.

100. Fairweather D, Coronado MJ, Garton AE, Dziedzic JL, Bucek A, Cooper LT Jr, et al. Sex differences in translocator protein $18 \mathrm{kDa}$ (TSPO) in the heart: implications for imaging myocardial inflammation. J Cardiovasc Transl Res. 2014;7:192-202.

101. Kim GR, Paeng JC, Jung JH, Moon BS, Lopalco A, Denora N, et al. Assessment of TSPO in a rat experimental autoimmune myocarditis model: a comparison study between $\left[{ }^{18} \mathrm{~F}\right]$ fluoromethyl-PBR28 and $\left[{ }^{18} \mathrm{~F}\right] \mathrm{CB} 251$. Int J Mol Sci. 2018; 19:276.

102. Thai PN, Daugherty D, Frederich BJ, Galice S, Deng W, Bers $\mathrm{DM}$, et al. Emerging role of the mitochondrial outer membrane translocator protein (TSPO) in heart failure and mitochondrial quality control. Biophys J. 2017;112:325a.

103. Thai PN, Daugherty DJ, Frederich BJ, Lu X, Deng W, Bers $\mathrm{DM}$, et al. Cardiac-specific conditional knockout of the $18-\mathrm{kDa}$ mitochondrial translocator protein protects from pressure overload in induced heart failure. Sci Rep. 2018;8:16213.

104. Halestrap AP. What is the mitochondrial permeability transition pore? J Mol Cell Cardiol. 2009;46:821-31.

105. Narayan N, Owen D, Mandhair H, Smyth E, Carlucci F, Saleem A, et al. Translocator protein as an imaging marker of macrophage and stromal activation in RA pannus. J Nucl Med. 2018;59:1125-32.

106.••Borchert T, Hess A, Lukačević M, Ross TL, Bengel FM, Thackeray JT. Angiotensin-converting enzyme inhibitor treatment early after myocardial infarction attenuates acute cardiac and neuroinflammation without effect on chronic inflammation. Eur J Nucl Med Mol Imaging. 2020;47:1757-1768. The authors demonstrate in this pre-clinical study that application of an ACE inhibitor to a model of acute myocardial infarction reduces TSPO PET signal and correlates with improved cardiac function. Significantly, this study suggests that TSPO PET might serve as a predictive imaging biomarker in assessing cardiac health and monitoring response to therapy.

107. MacAskill MG, Stadulyte A, Williams L, Morgan TFF, Sloan NL, Alcaide-Corral CJ, et al. Quantification of macrophagedriven inflammation during myocardial infarction with ${ }^{18}$ F-LW223, a novel TSPO radiotracer with binding independent of the rs6971 human polymorphism. J Nucl Med. 2021;62:536-44.

108. Fairweather D, Guilarte TR, Cooper LT Jr. Biomarker and more: can translocator protein $18 \mathrm{kDa}$ predict recovery from brain injury and myocarditis? Biomark Med. 2014;8:605-7.

109. Fernández-Ruiz I. New insights from PET imaging. Nature Rev Cardiol. 2018;15:135.

110. Gyöngyösi M, Lukovic D, Zlabinger K, Spannbauer A, Gugerell A, Pavo N, et al. Liposomal doxorubicin attenuates cardiotoxicity via induction of interferon-related DNA damage resistance. Cardiovasc Res. 2020;116:970-82.

111. de Tassigny Ad, Assaly R, Schaller S, Pruss RM, Berdeaux A, Morin D.. Mitochondrial translocator protein (TSPO) ligands prevent doxorubicin-induced mechanical dysfunction and cell death in isolated cardiomyocytes. Mitochondrion. 2013;13:688-697. 
112. Pecoraro M, Del Pizzo M, Marzocco S, Sorrentino R, Ciccarelli $\mathrm{M}$, Iaccarino $\mathrm{G}$, et al. Inflammatory mediators in a short-term mouse model of doxorubicin-induced cardiotoxicity. Toxicol Appl Pharmacol. 2016;293:44-52.

113. Doring Y, Pawig L, Weber C, Noels H. The CXCL12/CXCR4 chemokine ligand/receptor axis in cardiovascular disease. Front Physiol. 2014;5:212.

114. Wang ER, Jarrah AA, Benard L, Chen J, Schwarzkopf M, Hadri L, Tarzami ST. Deletion of CXCR4 in cardiomyocytes exacerbates cardiac dysfunction following isoproterenol administration. Gene Ther. 2014;21:496-506.

115. LaRocca TJ, Altman P, Jarrah AA, Gordon R, Wang E, Hadri $\mathrm{L}$, et al. CXCR4 cardiac specific knockout mice develop a progressive cardiomyopathy. Int J Mol Sci. 2019;20:2267.

116. Jujo K, Hamada H, Iwakura A, Thorne T, Sekiguchi H, Clarke $\mathrm{T}$, et al. CXCR4 blockade augments bone marrow progenitor cell recruitment to the neovasculature and reduces mortality after myocardial infarction. Proc Natl Acad Sci USA. 2010;107:11008-13.

117. Glasenapp A, Derlin K, Gutberlet M, Hess A, Ross TL, Wester $\mathrm{H}-\mathrm{J}$, et al. Molecular imaging of inflammation and fibrosis in pressure overload heart failure. Circ Res. 2021;129:369-82.

118. Thackeray JT, Derlin T, Haghikia A, Napp LC, Wang Y, Ross TL, et al. Molecular imaging of the chemokine receptor CXCR4 after acute myocardial infarction. JACC Cardiovasc Imaging. 2015;8:1417-26.

119. Zacherl MJ, Todica A, Wängler C, Schirrmacher R, Hajebrahimi MA, Pircher J, et al. Molecular imaging of cardiac CXCR4 expression in a mouse model of acute myocardial infarction using a novel ${ }^{68} \mathrm{Ga}$-mCXCL12 PET tracer. J Nucl Cardiol. 2020. https://doi.org/ 10.1007/s12350-020-02262-6.

120. Reiter T, Kircher M, Schirbel A, Werner RA, Kropf S, Ertl $\mathrm{G}$, et al. Imaging of C-X-C motif chemokine receptor CXCR4 expression after myocardial infarction with $\left[{ }^{68} \mathrm{Ga}\right]$ Pentixafor$\mathrm{PET} / \mathrm{CT}$ in correlation with cardiac MRI. JACC Cardiovasc Imaging. 2018;11:1541-3.

121. Farhad H, Staziaki PV, Addison D, Coelho-Filho OR, Shah RV, Mitchell RN, et al. Characterization of the changes in cardiac structure and function in mice treated with anthracyclines using serial cardiac magnetic resonance imaging. Circ Cardiovasc Imaging. 2016;9:e003584.

122. Meléndez GC, Hundley HG. Is myocardial fibrosis a new frontier for discovery in cardiotoxicity related to the administration of anthracyclines? Circ Cardiovasc Imaging. 2016;9:e005797.

123. Krenning G, Zeisberg EM, Kalluri R. The origin of fibroblasts and mechanism of cardiac fibrosis. J Cell Physiol. 2010;225:631-7.

124. Stuart SDF, De Jesus NM, Lindsey ML, Ripplinger CM. The crossroads of inflammation, fibrosis, and arrhythmia following myocardial infarction. J Mol Cell Cardiol. 2016;91:114-22.

125. López B, González A, Ravassa S, Beaumont J, Moreno MU, San José G, et al. Circulating biomarkers of myocardial fibrosis. J Am Coll Cardiol. 2015;65:2449-56.

126. Langer LBN, Hess A, Korkmaz Z, Tillmanns J, Reffert LM, Bankstahl JP, et al. Molecular imaging of fibroblast activation protein after myocardial infarction using the novel radiotracer $\left[{ }^{68} \mathrm{Ga}\right]$ MHLLI. Theranostics. 2021;11:7755-66.

127. Prabhu SD, Frangogiannis NG. The biological basis for cardiac repair after myocardial infarction: from inflammation to fibrosis. Circ Res. 2016;119:91-112.

128. Ma Y, Iyer RP, Jung M. Cardiac fibroblast activation postmyocardial infarction: current knowledge gaps. Trends Pharmacol Sci. 2017;38:448-58.

129. Nagaraju CK, Dries E, Popovic N, Singh AA, Haemers P, Roderick HL, et al. Global fibroblast activation throughout the left ventricle but localized fibrosis after myocardial infarction. Sci Rep. 2017;7:10801.
130. Tillmanns J, Hoffmann D, Habbaba Y, Schmitto JD, Sedding D, Fraccarollo D, et al. Fibroblast activation protein alpha expression identifies activated fibroblasts after myocardial infarction. J Mol Cell Cardiol. 2015;87:194-203.

131. Tillmanns J, Fraccarollo D, Galuppo P, Wollert KC, Bauersachs $\mathrm{J}$. Changes in concentrations of circulating fibroblast activation protein alpha are associated with myocardial damage in patients with acute ST-elevation MI. Int J Cardiol. 2017;232:155-9.

132. Goldsmith EC, Doviak H, Perreault PE, Swimmer KR, Zellars $\mathrm{KN}$, Barlow $\mathrm{S}$, et al. Identification and putative function of fibroblast activation protein and relevance to post-myocardial infarction remodeling. Circulation. 2016;134:A19686.

133. Notohamiprodjo S, Nekolla SG, Robu S, Villagran Asiares A, Kupatt C, Ibrahim T, et al. Imaging of cardiac fibroblast activation in a patient after acute myocardial infarction using ${ }^{68}$ Ga-FAPI-04. J Nucl Cardiol. 2021. https://doi.org/10.1007/ s12350-021-02603-Z.

134. Varasteh Z, Mohanta S, Robu S, Braeuer M, Li Y, Omidvari $\mathrm{N}$, et al. Molecular imaging of fibroblast activity after myocardial infarction using a ${ }^{68} \mathrm{Ga}$-labeled fibroblast activation protein inhibitor, FAPI-04. J Nucl Med. 2019;60:1743-9.

135. Kratochwil C, Fleschig P, Lindner T, Abderrahim L, Altmann A, Mier W, et al. ${ }^{68} \mathrm{Ga}$-FAPI PET/CT: Tracer Uptake in 28 Different Kinds of Cancer. J Nucl Med. 2019;60:801-5.

136. Zhu W, Guo F, Wang Y, Ding H, Huo L. ${ }^{68}$ Ga-FAPI-04 accumulation in myocardial infarction in a patient with neuroendocrine carcinoma. Clin Nucl Med. 2020;45:1020-2.

137. Yuan T, Wang X. ${ }^{68} \mathrm{Ga}$-FAPI PET/MRI in coronary heart disease. $\mathrm{J}$ Nucl Cardiol. 2021. https://doi.org/10.1007/s12350-021-02667-x.

138. Totzeck M, Siebermair J, Rassaf T, Rischpler C. Cardiac fibroblast activation detected by positron emission tomography/computed tomography as a possible sign of cardiotoxicity. Eur Heart J. 2020;41:1060.

139. Siebermair J, Köhler MI, Kupusovic J, Nekolla SG, Kessler L, Ferdinandus J, et al. Cardiac fibroblast activation detected by Ga-68 FAPI PET imaging as a potential novel biomarker of cardiac injury/remodeling. J Nucl Cardiol. 2021;28:812-21.

140.•Heckmann MB, Reinhardt F, Finke D, Katus HA, Haberkorn U, Leuschner F, Lehmann LH. Relationship Between Cardiac Fibroblast Activation Protein Activity by Positron Emission Tomography and Cardiovascular Disease. Circ Cardiovasc Imaging. 2020;13:e010628. This retrospective study demonstrates increased FAPI PET signal in cancer patients with cardiovascular risk factors, including those treated with anthracyclines or chest irradiation, a finding that implies that this modality can image incipient cardiac damage in cardio-oncology. Increased FAPI PET signal is associated with decreased LVEF in a cohort of these patients, suggesting that it may indeed be a predictive imaging biomarker of cardiotoxicity.

141. Balasubramanian S, Quinones L, Kasiganesan H, Zhang Y, Pleasant DL, Sundararaj KP, et al. $\beta 3$ Integrin in Cardiac Fibroblast Is Critical for Extracellular Matrix Accumulation during Pressure Overload Hypertrophy in Mouse. PLoS ONE. 2012;7:e45076.

142. Higuchi T, Bengel FM, Seidl S, Watzlowik P, Kessler H, Hegenloh $\mathrm{R}$, et al. Assessment of $\alpha_{\mathrm{v}} \beta_{3}$ integrin expression after myocardial infarction by positron emission tomography. Cardiovasc Res. 2008;78:395-403.

143. Jenkins WSA, Vesey AT, Stirrat C, Connell M, Lucatelli C, Neale A, et al. Cardiac $\alpha_{v} \beta_{3}$ integrin expression following acute myocardial infarction in humans. Heart. 2017;103:607-15.

144. Jenkins WS, Vesey AT, Vickers A, Neale A, Moles C, Connell M, et al. In vivo alpha-V beta-3 integrin expression in human aortic atherosclerosis. Heart. 2019;105:1868-75.

145. Doenst T, Nguyen TD, Abel ED. Cardiac Metabolism in Heart Failure. Circ Res. 2013;113:709-24. 
146. Tamaki N, Morita K, Kuge Y, Tsukamoto E. The role of fatty acids in cardiac imaging. J Nucl Med. 2000;41:1525-34.

147. Mäki MT, Haaparanta M, Nuutila P, Oikonen V, Luotolahi M, Eskola O, Knuuti JM. Free fatty acid uptake in the myocardium and skeletal muscle using fluorine-18-Fluoro-6-Thia-heptadecanoic acid. J Nucl Med. 1998;39:1320-7.

148. Christensen NL, Jakobsen S, Schacht AC, Munk OL, Alstrup AKO, Tolbod LP, et al. Whole-body biodistribution, dosimetry, and metabolite correction of $\left[{ }^{11} \mathrm{C}\right]$ palmitate: a PET tracer for imaging of fatty acid metabolism. Mol Imaging. 2017; 16:1536012117734485.

149. Sobel BE, Weiss ES, Welch MJ, Siegel BA, Ter-Pogossian MM. Detection of remote myocardial infarction in patients with positron emission transaxial tomography and intravenous ${ }^{11} \mathrm{C}$-palmitate. Circulation. 1977;55:853-7.

150. Eisenberg JD, Sobel BE, Geltman EM. Differentiation of ischemic from nonischemic cardiomyopathy with positron emission tomography. Am J Cardiol. 1987;59:1410-4.

151. Geltman EM. Assessment of myocardial fatty acid metabolism with 1- ${ }^{11}$ C-palmitate. J Nucl Cardiol. 1994;1:S15-22.

152. Geltman EM, Smith JL, Beecher D, Ludbrook PA, Ter-Pogossian MM, Sobel BE. Altered regional myocardial metabolism in congestive cardiomyopathy detected by positron tomography. Am J Med. 1983;74:773-85.

153. Bergmann SR, Weinheimer CJ, Markham J, Herrero P. Quantitation of myocardial fatty acid metabolism using PET. J Nucl Med. 1996;37:1723-30.

154. Shoghi KI, Finck BN, Schechtman KB, Sharp T, Herrero P, Gropler RJ, et al. In vivo metabolic phenotyping of myocardial substrate metabolism in rodents. Circ Cardiovasc Imaging. 2009;2:373-81.

155. Li Y, Huang T, Zhang X, Zhong M, Walker NN, He J, et al. Determination of fatty acid metabolism with dynamic ${ }^{11} \mathrm{C}$-palmitate positron emission tomography of mouse heart in vivo. Mol Imaging. 2015;14:516-25.

156. de Jong HWAM, Rijzewijk LJ, Lubberink M, van der Meer RW, Lamb HJ, Smit JWA, et al. Kinetic models for analysing myocardial $\left[{ }^{11} \mathrm{C}\right]$ palmitate data. Eur J Nucl Med Mol Imaging. 2009;36:966-78.

157. Gormsen LC, Svart M, Thomsen HH, Søndergaard E, Vendelbo MH, Christensen N, et al. Ketone body infusion with 3-hydroxybutyrate reduces myocardial glucose uptake and increases blood flow in humans: a positron emission tomography study. J Am Heart Assoc. 2017;6:e005066.

158. DeGrado TR, Coenen HH, Stöcklin G. $\left.14(\mathrm{R}, \mathrm{S}){ }_{-}{ }^{[1} 8 \mathrm{~F}\right]$ Fluoro6-Thia-heptadecanoic acid (FTHA): evaluation in mouse of a new probe of myocardial utilization of long chain fatty acids. $\mathbf{J}$ Nucl Med. 1991;32:1888-96.

159. Knust EJ, Kupfernagel C, Stöcklin G. Long-Chain F-18 Fatty acids for the study of regional metabolism in heart and liver; oddeven effects of metabolism in mice. J Nucl Med. 1979;20:1170-5.

160. Taylor M, Wallhaus TR, DeGrado TR, Russell DC, Stanko P, Nickles RJ, Stone CK. An evaluation of myocardial fatty acid and glucose uptake using PET with $\left[{ }^{18} \mathrm{~F}\right]$ fluoro-6-thia-heptadecanoic acid and $\left[{ }^{18} \mathrm{~F}\right] \mathrm{FDG}$ in patients with congestive heart failure. $\mathrm{J}$ Nucl Med. 2001;42:55-62.

161. DeGrado TR, Wang S, Holden JE, Nickles RJ, Taylor M, Stone CK. Synthesis and preliminary evaluation of ${ }^{18} \mathrm{~F}$-labeled 4-thia palmitate as a PET tracer of myocardial fatty acid oxidation. Nucl Med Biol. 2000;27:221-31.
162. DeGrado TR, Bhattacharyya F, Pandey MK, Belanger AP, Wang S. Synthesis and preliminary evaluation of ${ }^{18} \mathrm{~F}$-fluoro-4thia-oleate as a PET probe of fatty acid oxidation. J Nucl Med. 2010;51:1310-7.

163. Ohshima Y, Yagi Y, Chen X, Muhlig S, Fushiki H, Murakami $Y$, Higuchi $T$. In vitro characterization of a novel PET tracer for fatty acid oxidation, ${ }^{18} \mathrm{~F}-\mathrm{AS} 3504073-00$. J Nucl Med. 2020;61(Suppl1):222.

164. O'Farrell AC, Evans R, Silvola JMU, Miller IS, Conroy E, Hector $\mathrm{S}$, et al. A novel positron emission tomography (PET) approach to monitor cardiac metabolic pathway remodeling in response to sunitinib malate. PLoS One. 2017;12:e0169964.

165. Croteau E, Tremblay S, Gascon S, Dumulon-Perreault V, Labbé SM, Rousseau JA, et al. $\left[{ }^{11} \mathrm{C}\right]$-Acetoacetate PET imaging: a potential early marker for cardiac heart failure. Nucl Med Biol. 2014;41:863-70.

166. Evans JD, Gomez DR, Chang JY, Gladish GW, Erasmus JJ, Rebueno N, et al. Cardiac ${ }^{18} \mathrm{~F}$-fluorodeoxyglucose uptake on positron emission tomography after thoracic stereotactic body radiation therapy. Radiother Oncol. 2013;109:82-8.

167. Jingu K, Kaneta T, Nemoto K, Ichinose A, Oikawa M, Takai Y, et al. The Utility of ${ }^{18} \mathrm{~F}$-Fluorodeoxyglucose positron emission tomography for early diagnosis of radiation-induced myocardial damage. Int J Radiat Oncol Biol Phys. 2006;66:845-51.

168. Sarocchi M, Bauckneht M, Arboscello E, Capitanio S, Marini C, Morbelli S, et al. An increase in myocardial 18-fluorodeoxyglucose uptake is associated with left ventricular ejection fraction decline in Hodgkin lymphoma patients treated with anthracycline. J Trans Med. 2018;16:295. This study identifies a metabolic component of cardiotoxicity by demonstrating an inverse relationship between left ventricular $\left[{ }^{18}\right.$ F]FDG uptake and LVEF in patients receiving doxorubicin chemotherapy. Although the study is retrospective rather than prospective, it highlights the potential value of metabolic PET imaging as an early indicator of cardiotoxicity in a young population of cancer patients.

169. Bauckneht M, Cossu V, Miceli A, Donegani MI, Capitanio S, Morbelli S, et al. FDG-PET imaging of doxorubicin-induced cardiotoxicity: a new window on an old problem. Curr Cardiovasc Imaging Rep. 2019;12:41.

170. Armbrecht J, Buxton DB, Brunken RC, Phelps ME, Schelbert HR. Regional myocardial oxygen consumption determined noninvasively in humans with $\left[1-{ }^{11} \mathrm{C}\right]$ acetate and dynamic positron emission tomography. Circulation. 1989;80:863-72.

171. Tadamura E, Tamaki N, Matsumori A, Magata Y, Yonekura Y, Nohara R, et al. Myocardial metabolic changes in hypertrophic cardiomyopathy. J Nucl Med. 1996;37:572-7.

172. Timmer SAJ, Lubberink M, Germans T, Götte MJW, ten Berg $\mathrm{JM}$, ten Cate FJ, et al. Potential of $\left[{ }^{11} \mathrm{C}\right]$ acetate for measuring myocardial blood flow: studies in normal subjects and patients with hypertrophic cardiomyopathy. J Nucl Cardiol. 2010;17:264-75.

173. Herrero P, Dence CS, Coggan AR, Kisrieva-Ware Z, Eisenbeis P, Gropler RJ. L-3- ${ }^{11} \mathrm{C}$-Lactate as a PET tracer of myocardial lactate metabolism: a feasibility study. J Nucl Med. 2007;48:2046-55.

174. Tong D, Zaha VD. Metabolic imaging in cardio-oncology. J Cardiovasc Trans Res. 2020;13:357-66.

Publisher's Note Springer Nature remains neutral with regard to jurisdictional claims in published maps and institutional affiliations. 